\title{
Interview
}

\section{In conversation with Lord Seebohm}

Hugh Freeman interviewed Lord Seebohm at his home in London in February 1989.

HF Would I be right in thinking that your long interest in the welfare of other people has something to do with a Quaker background?

LS I suppose it has really. When I came back from the War, I was sent up to work in York and that is

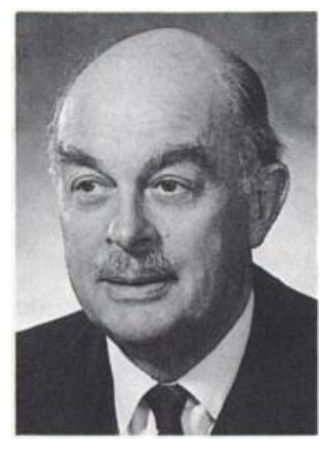
where, being a Quaker, I was contacted by the Joseph Rowntree Memorial Trust in 1949. I became a trustee, and since then, have been very closely involved with all the work of the Trust. It is a very big one, covering almost all aspects of social problems.

HF The aspect which is of most interest to us is psychiatry. Yours, I think, is that of the Personal Social Services and of course the Seebohm Report. Could you tell me when you first became involved in that particular field?

LS It started when the Joseph Rowntree Memorial Trust and the Nuffield Foundation got together to form the National Institute of Social Work Training. I was one of the founder members, and became the initial Chairman. That was back in 1962, as a result of the Younghusband Report.

HF It was a direct consequence of the Younghusband Report?

LS Yes it was. The Report recommended that the institute should be started, and that got me fairly heavily involved in the training of social workers. Naturally I also got involved with certain personalities who were rather close to Whitehall, and when the Seebohm Committee was mooted, my name was put forward as a suitable person to be Chairman. Also, I think they took into account that I was a fairly prominent businessman and knew something about management, and that I was not likely to be a visionary - although in due course, we were in fact accused of being visionary!
HF In the evidence you heard, would you say that mental health social work figured prominently, or was it rather in the background?

LS Not really prominently. We were interested in bringing the mental health social workers into the personal social services, as opposed to the health side, but I think otherwise, we did not really give a great special thought to mental health or psychiatric problems. One of the interesting things in our report, though, was about the under-fives. We had long sessions with people from the Tavistock Institute, who stressed the vast importance of care for that age-group. However, a recent report, I think by Gillian Pugh, on the under-fives shows how little this has in fact progressed. To me, the role of the psychiatric services with them is incredibly important; it affects the whole life of the individual.

HF Do you think that psychiatric social work, which had established a clear identity of its own by that time, really had a fair hearing, or that it got its case over adequately?

LS I really don't know. I regarded psychiatric social work as extremely important, not least because I had a daughter who became a psychiatric social worker for a time. In fact, she told me that had made a great difference to her life and to her understanding of problems.

HF Up to that time, there had been some determined efforts in certain places to create a unified mental health service, in which psychiatric social work was closely integrated with the medical, nursing, and other professions. However, when your recommendations took the PSWs out of mental health departments into unified social services, these integrated mental health services were in fact broken up, and many people felt strongly that this had some negative effects. Was that aspect of things looked at in any detail?

LS I don't think it was; perhaps that was a weakness in the Report. The whole problem of dealing with people with mental health problems was very much in a state of flux at that time. Up to then, there was very little attempt to bring any of these people who were in hospitals and institutions back into the community. Perhaps our report was a little premature in a 
sense, because I don't think the whole problem had really been carefully enough studied at that time. Since then, of course, it has had a great deal more prominence.

HF At that time, there was already a lot of discussion about the possibility of community care and community services, but one of the requirements of these would be a larger number of well-trained social workers, with particular kinds of experience. At the time of the report, did you feel the country as a whole could be served by a service of generic social workers?

LS No. And I think there has been a major misinterpretation of the report to that effect. What we did say, though we obviously didn't spell it out clearly enough or the mistake would not have arisen, was that the area teams would be themselves generic. This didn't mean they'd have no specialists, and we in fact said that they should have a mental health specialist within the team, or at least have contact at headquarters with the necessary specialists. But we also were very conscious, when we talked to people concerned, that a lot of the skills ought to be within the normal armoury of a trained social worker. And of course, we also made it perfectly clear that we had no idea in 1968 what future specialists would be required. That has proved only too true with child abuse, with mental health for that matter, with the elderly in much larger numbers, and with the very young. These specialities have all gradually matured, and to a certain extent been developed.

HF Did you feel that the financial implications of the report might be rather serious in the future? Up to that time, the late 1960s, social workers were very badly paid, but if they were to become true professionals and be on any thing like terms of equality with other professions, they were going to need a tremendous boost in reward. Did you feel that this had important implications for the future?

LS Very much so. We gave considerable thought to the question of whether you could really call social work a profession at that stage. I personally felt that after we had introduced the Younghusband courses, and training had been much improved in the years between 1962 and 1965 , when we started work, that in fact it was a profession and not, as the doctors usually called it, just a paramedical force of workers. We worked on that basis, and since then, training has been considerably expanded. As far as resources are concerned, we made no bones of the fact that much more would be required, not only because we wanted to have a more qualified force, but because we anticipated that a vast amount of unmet needs would be uncovered, which in fact was what happened. The moment they were decentralised from the town hall, the demand on social services increased enormously, and I was very gratified at the extent to which extra resources were in fact made available then. Now, we have four times as many social workers as we had in 1968, and the amount spent on the personal social services, in real terms, has doubled. It's still not all that great, though; in 1965-1966, it was only 0.72 of GDP - a very small $1.5 \%$ of national expenditure. It's a little bit more now, but not so vast an amount. Of course, the national wealth has increased, so that although the numbers of people employed and the facilities have grown, as a proportion of GDP and national expenditure, they remain just about the same. Of course, what Griffiths has recommended would mean that a lot more resources would be needed, and in your field, if a lot of cases are to be transferred into the community, they have got to have the caring services envisaged. In that case, the cost would actually be greater than that of leaving people in hospital. There's no saving there.

HF No. Would you say in general, with the social services, that things have happened as you thought they would in 1968 , or have there been any particular ways in which they have diverged strongly from your predictions?

LS To start with, they did not adopt our recommendation on the point of having more qualified administrators at the top. We did say that there should either be social workers with administrative experience or administrators with some social work experience, in these posts. The vast majority who were appointed, though, were children's officers, who were very good professionally, but they had not got administrative knowledge. The result was that it all started off in a very uncertain way, but over the years, the position has improved out of all recognition. The Directors of Social Services now, in my view, are a very fine lot, but they have got a whole new role to learn in resource management and contracting out, which again is going to start an entirely different field of training. I understand that the Central Council for Education and Training in Social Work is, in fact, trying to formulate some such scheme and analyse its implications. I will be interested to know what comes out of that. They have been turned down in their request for a third year of training for social workers, though that doesn't necessarily mean they aren't going to have a 
'sandwich', to make a third year of some sort, which I hope they will achieve.

HF What do you feel about the balance between professional authority and administrative authority? It's a long-standing debate in medicine, of course, and generally speaking, doctors here have been able to practise without an administrative hierarchy above them; they have achieved autonomy in that respect. Do you think that in social work, professional skills have been subordinated to administrative requirements?

LS I wouldn't say so. I think being a comparatively new service, they have had a fairly free run on how to organise themselves, but the requirements of different parts of the country are entirely different. Go to a borough like Islington, for instance, which has a population of approximately 160,000 , and they've got 25 purpose-built social work centres, in each of which there is a health worker and a housing officer. This is actually ideal for London, though very expensive, I think. In a place like Hertfordshire or Hampshire, where they have got a million and a half population scattered around, with perhaps half a dozen major cities and towns, the problem is entirely different. So it's very difficult to generalise where success has shown up and where it hasn't because these things can't be proved, but London is always different.

HF How do you feel the relationship with the voluntary sector to public services has changed, and how do you see it in the future?

LS One of the disappointments, to my mind, is that there has not been a close enough association between the personal social services and both individual volunteers and voluntary organisations. But I think it's going to become very much closer now, because in contracting out, voluntary organisations are going to be the prime people who will try to take this on. It may grow very fast. Of course, local authorities have been given vastly increased revenue since the Seebohm Report, when they took responsibility for many voluntary organisations. This was to a certain extent the result of the Wolfenden Report on these organisations, which was a very good one indeed. In fact, the increase in local authority support for voluntary organisations in the decade from 1970 to 1980 was five times, and I imagine it has been increased further since then. Now, quite a number of them are probably in a position to help contracting out considerably. Again, though, there will have to be a good deal of extra training to equip them to do it. It's going to be a very difficult process. First of all, the social services have got to cost their own performance, and then they have got to produce some sort of contract document, which will have to set an acceptable standard.

HF One of the things that worries us in psychiatry is that with the transfer of handicapped people from institutions to the community, they will be dependent on locally organised social services and to some extent voluntary services, which are sometimes at the whim of political changes or financial problems locally. Whereas we were promised a large increase in the local authority contribution to mental health services, in some cases there has been in fact a decrease recently.

LS The problem, as Griffiths pointed out, is that the health services have had extra resources simply to help them finance extramural caring services whereas, as patients move towards the responsibility of the personal social services, no additional funds have been made available directly for that purpose. Now, it's probably going to come through the Government and not through rates, so somebody in Whitehall will have to decide how much they are going to give directly, if it is accepted that the personal social services are to look after this new caring service. I think this switch between health and social services is going to be rather difficult, unless the Government comes up with a lot more finance. I'm glad to say that quite considerable experiments are taking place now, and places like Hove, Darlington, and Kent have produced schemes. I know that in my territory of Hampshire, there is considerable co-operation between the health and personal social services in joint caring projects. But this has got to be put into a statutory form so that the money would definitely be there, and not just depend on good will. At the moment, a lot of schemes do depend just on good will.

HF There has just been a report showing that child guidance clinics are actually being closed or reduced in function at present, which is not encouraging. From the very beginning of the NHS, though, all governments have resisted the earmarking of funds specially for mental health services in the community. It has always been left for local decisions, and as psychiatrists, we have felt that things would never really get better throughout the country unless there was a clear identification of funds for these services.

LS That is what is under discussion now - the transfer of funds from the health to social services to look after the proposed caring service, but I think that more may have to be done there, because the degree of flexibility 
available to local authorities in finance is now so restricted. I think it has got to be developed further, and that there must indeed be some positive direction of money, if we are going to get away from an extremely patchy service.

HF One of our worries about Griffiths has been that it seems sometimes to confuse the care of illness with the care of disability, because many people with mental illness have both. Yet it seems to lean too far to a caring model rather than to a treating model.

LS What you say is absolutely true, I'm sure. One of the things that we suspected when we were doing the Seebohm Report was that the local authority health services were going to be transferred to the NHS, and this is why we didn't make any specific suggestions that there should be combined health and welfare service. A lot of local authorities had already combined them, which in a sense meant that we had less to put together. Although we were fairly certain that the combination of NHS and local health services was going to happen, I don't think the medical profession at that stage seemed to realise it. The doctors hated Seebohm - still do, I think!

HF I think the bitterness was largely restricted to public health doctors. I don't think that doctors in general were against it, though psychiatrists were very worried about the break-up of some of the integrated mental health services. But commentators from other countries have often remarked on the split between health services and social services in this country, which are under separate administrations, and have wondered why we didn't combine them. The usual answer, I think, is that it would make too big an organisation.

LS Well, in America, they have HEW, which is Health, Education and Welfare, and quite frankly, it's a bit of a mess. It's far too big a thing to put all together. What one should have is something which is containable and can make a real impact. If it contains too many things, too many duties and functions, it will probably not get down to fundamentals. That was one of things we felt on the Committee why we combined services to make a very identifiable thing, and why we were very keen to separate raising cash from providing care. I think once you get those two things involved, you are in great difficulty. When I gave one or two lectures in America, they couldn't understand me at all; they had no idea there was any difference. 'What you haven't got, you can buy' is the American theory. They really believe that!
HF On that point, what do you feel about the tremendous growth in private accommodation for old people, the mentally ill, and others?

LS Now we come on to the Wagner Report. I think this process is dangerous, frankly. It's so difficult to supervise over the whole field, and is growing very fast, yet the theory that old people have choice is not really true. A lot of them think how marvellous it would be to go into a home and have no more worries, but when they get there, it's often not what they expected at all. On the other hand, there are a lot of people who believe that they should stay in their home with their own things, but in fact, if they really had the offer to go to a nice residential home, you wouldn't see them for dust. There are a lot of nuances in this particular argument, which tend to be ignored, but what I think is the danger is the very rapid growth in private facilities, which the Government are supporting by their benefit payments. Because the way it's done - making it a profitable enterprise-and the way it's growing, you can't expect them all to be thoroughly socially motivated. I think it's all a bit dangerous.

HF I know you have had a number of other interests in the welfare and voluntary sector, including the Volunteer Centre. Are there any others you would like to comment on?

LS One of the things that came up recently and which we have been engaged on in the House of Lords, is the role of housing associations. I believe that it's better to subsidise people than bricks and mortar, but on the other hand, you do need both. You can't get away from the fact that there must be some publicly owned, rented property. The housing associations have been run by properly motivated people, very well helped and managed by the National Federation of Housing Associations and the Housing Corporation, but I have a nasty feeling that the latest Acts will rather change their character and make it more difficult for them to do what they have really set out to do. My feeling is that housing has been in a mess since the beginning of time; the enquiry in 1885 produced exactly the same report as the Duke of Edinburgh's in 1985. It's still in a mess, and I don't think any government has really faced up to the fact that for $20 \%$ of the population, housing has to be a social service. I've always held that view. In his model village, Joseph Rowntree did it as economically as it was possible to do with ordinary cottages and open streets, but he found that even on a $2 \frac{1}{2} \%$ return basis, they couldn't in fact let those units to the people with low incomes in York. So for a long 
time, it was subsidised, and this disappointed Rowntree a lot, because he really tried to show that you could produce low-rent accommodation for all without subsidy, and he found it wasn't possible.

HF Do you think the present housing policy allows sufficiently for the handicapped - for instance, people with chronic mental illness who are leaving hospital? Is more specific help really needed for these people?

LS There's nothing like enough rented accommodation, even for the physically handicapped. In a recent debate in the House of Lords, there was no consensus on this, but the tide of opinion was much more towards giving handicapped people the right to buy, which I think is probably right, but only as long as more homes are built, of which I see no indication at present. I would like to know more about what the plans are for those who have mental handicaps, as opposed to physical ones. Because they can't live alone, you can't really expect each one to have a personal carer living with them all the time; this would be an extraordinarily expensive way of living, though quite a lot of fostering is possible - rather more than I used to think. I still believe you have got to have small establishments, for about a dozen people, where a very small staff can help to look after them. That sort of organisation seems to have been rather overlooked.

HF I think you're right about that. Some rather unrealistic attempts have been made to rehouse both mentally ill and mentally handicapped people, either singly or in pairs, with a huge amount of support; this is not very satisfactory for them, and of course creates enormous costs to the services. I think there should be more opportunities for small groups, in fairly domestic kinds of accommodation.

LS Yes, that's what I would have thought.

HF Could I ask you how you see the present trends in our society, particularly in relation to the interests that you have pursued for so long?

LS I've just been looking at the demographic changes between 1968 and 1988-20 years. Somebody once said to me that the biggest influence on change in our society was the invention of the Pill. I don't know if I agree entirely with that, but one major change is the vast number of single-parent families, related to the very high divorce rate. And so you get these extraordinary situations with stepparents, step-children, step-grandparents, and mixed-up families, which I would think are going to have a bad effect on society. The other demographic change, of course, has been the increasingly mixed society, as a result of immigration. In 1968, one wasn't particularly worried about it, but now, it's another great addition to the problems that the personal services have to deal with. These have been combined with unemployment, which didn't exist in 1968; in fact, there was over-employment then.

The other thing that I think has not helped us is that in the last few years, there has been a very rapid growth in commercial prosperity, which has raised everyone's expectations too high. There's an element of overt greed about, which I don't think really existed so much in 1968 , when we were still perhaps influenced by the war. One view is that growth in prosperity amongst one part of the economy produced what they call 'trickle down' - it helps everybody. That's just not true. It has never happened in the Third World, even when there has been this rapid growth; certainly in Nigeria, $75 \%$ are even worse off than they were 50 years ago. So I think there has to be some sort of transfer of wealth - a normal way is taxation.

One of the things I feel very strongly about is child benefit; for that age-group, it's terribly important that they have full support, but families are not going to be better off by a new system of family credit. I believe that child benefit was a most wonderful, far-seeing thing, which should be increased, and not blighted on the vine. The near-poor are really very poor when they have a family of children, and the expenses are so unpredictable then-new clothes regularly or the cost of illness. It's very difficult life for parents, and since child benefit was greeted so enthusiastically by all parties at the time it was introduced, it's a pity that it's now been withered away.

HF When the York poverty survey was donewhich I imagine was by a relative of yours poverty was the lot of a large proportion of the working class. It was almost normal. The situation has now changed, in that severe poverty is the feature of a minority of the population. How has that change affected social policy, do you think?

LS This is very difficult, because with the advance of technology, people with no real skills, which accounts for about $60 \%$ of the population here, are going to suffer very much. Therefore, I think this is where the Government is doing a good job, through YTS and other schemes, to see that people are taught some sort of skills, so that they are in fact employable. In Germany, $60 \%$ of all the people aged 18 have got a vocational qualification, and in this country it's $30 \%$. When it does happen that we get a much more highly skilled workforce, this 
will enable business to expand much faster and small businesses to start up from the ground. Otherwise, I think the future for a lot of people here will be very gloomy. I'm President of a thing called Project Fullemploy. We have found that it's quite extraordinary how people who have been unemployed for a number of years, or even all their adult lives, such as those aged around 25 who have never had a job of any kind, suddenly develop most extraordinary abilities when they are taught to work together with others. I could give examples of these who had never had a job before, but who are now holding very big managerial posts in business. The so-called 'unskilled' can be made skilled in very much quicker time than most people think. In France, after the war, when they had to rebuild everything, instead of having a five-year apprenticeship, they found they could train people to be highly skilled in 18 months. I think there is terrific scope to give really good vocational training to all those leaving school.

HF Although the country is perhaps not doing so well in that sphere, do you think we have lessons to teach other parts of the world in our social policies?

LS I have found enormous interest overseas in the Seebohm Report and in the way we run our social services, though we've also got an awful lot to learn from others. I think the EC will have a major influence on thinking in this country; it has already done so on things like part-time work. I'm hoping it will, anyway.

HF As a Quaker, do you feel that religion has a significant part to play in our social affairs today?

LS I think it's sadly diminished. A few years ago, I was approached by a representative of the Church of England who said that morale amongst the clergymen was at an all-time low; and he asked what did I think their role was? I said, well for heaven's sake, don't become social workers. On the other hand, if I was to put pins in a map wherever there was a clergyman, you wouldn't see the map for pins, so they must have a role at least as a spotter of human problems or enabler. I don't believe they have really risen to that challenge yet. But obviously, there's a very sad diminution in religious teaching; knowledge of the Bible and of Christianity is abysmal.

HF As a banker, do you think that business, the City, and industry in this country play as much part as they could in relation to social problems in the general improvement of society?
LS They could do a lot more than they are doing, but they are already doing a lot. There's no doubt that the employees' buy-out principle, profit-sharing, and consulting by management with workers' councils have made enormous progress. Industrial relations are very much better than they ever were. Yet management, particularly I think in the medium-sized business, has been awfully slow to realise not only their responsibilities in this respect, but the potentiality it has for making a business successful. There are some fascinating examples, like the Toshiba plan in Plymouth, which is not run directly by the Japanese; they just laid down their principles and left it to the British managing director, and the result was incredible. First of all, they ensured the quality of the product at every stage instead of testing it when it came to the end of the line: whereas these works had previously had about a $\mathbf{4 0 \%}$ failure rate, now, when the products are inspected all the way along, $98 \%$ are absolutely perfect at the end of the production line. The second thing was that there must be a council representing the workforce, which meets regularly every month with the management, and that every proposed change is fully discussed, so that everybody understands what is happening and can express their views, though these are not always accepted. The management remains in control, but they listen very carefully to any objections that are raised to proposed changes; in fact, the management has taken a great deal of advice from this council.

HF Do you feel that business and management take sufficient account of social responsibilities, in the way perhaps that Rowntree and Seebohm did in the past?

LS No I don't, but I think it's growing very fast. For instance, there is what is called the One per cent Club of businesses, putting at least $1 \%$ of their profits away for social reasons. The amount that business is giving to charities now is enormous, compared with what it was 20 years ago. It's growing quite well, but there is a tremendous amount more to be done.

HF Could you project at all, or predict how you think these trends will effect our lives in the years to come?

LS Joseph Rowntree said, when he set up his trust, that "It's no good thinking that I can tell you what you ought to be doing in 25 years' time", and I must also refer you to J. R. Lovell's hymn - 'New Occasions Teach New Duties and Time Makes Ancient Good Uncouth!' 